\section{Distribution of Mycobacterium leprae genotypes from Surabaya and Bandung Clinical Isolates by Multiple Locus Variable Number of Tandem Repeat Analysis}

\author{
Cita Rosita Sigit Prakoeswa, ${ }^{1}$ \\ Bayu Bijaksana Rumondor, ${ }^{2}$ \\ Lina Damayanti, ${ }^{3}$ \\ Muljaningsih Sasmojo, ${ }^{3}$ \\ Dinar Adriaty, ${ }^{4}$ Medhi Denisa Alinda, ${ }^{1}$ \\ Ratna Wahyuni, ${ }^{4}$ \\ M. Yulianto Listiawan, ${ }^{1}$ \\ Indropo Agusni, ${ }^{1}$ Shinzo Izumi ${ }^{4}$ \\ ${ }^{1}$ Department of Dermatology and \\ Venereology, Faculty of Medicine \\ Universitas Airlangga, Dr Soetomo \\ Hospital, Surabaya; ${ }^{2}$ Faculty of \\ Medicine, Universitas Airlangga, Dr \\ Soetomo Hospital, Surabaya; \\ ${ }^{3}$ Department of Dermatology and \\ Venereology, Faculty of Medicine \\ Padjadjaran University, Dr Hasan \\ Sadikin Hospital, Bandung; ${ }^{4}$ Leprosy \\ Study Group, Tropical Diseases Center, \\ Universitas Airlangga, Surabaya, \\ Indonesia
}

\begin{abstract}
Multiple Locus Variable Number of Tandem Repeat (VNTR) analysis has been proposed as a means of genotyping for tracking leprosy transmission due to tandem repeats' potential as genetic markers to differentiate $M$. leprae strains. However, characteristics of polymorphism can vary depending on the population. This study aimed to compare the copy number of repeats in four genetic markers: TTC, AC8a, AC9 and 6-7 in leprosy patients from Surabaya and Bandung. Twenty three patients from Dr. Soetomo General Hospital and 21 from Hasan Sadikin Hospital were recruited. Multiple locus VNTR analysis was applied using total DNA extracts from Slit Skin Smear (SSS). From Surabaya, 7 samples showed the same copy number of four genetic markers $(\mathrm{TTC}=15 ; \mathrm{AC} 8 \mathrm{a}=10$; $\mathrm{AC} 9=10$ and $6-7=6$ ) and 2 showed another $(\mathrm{TTC}=16 ; \mathrm{AC} 8 \mathrm{a}=10 ; \mathrm{AC} 9=11$ and $6-7=6)$; as for samples from Bandung, 2 showed the same copy number $(\mathrm{TTC}=15 ; \mathrm{AC} 8 \mathrm{a}=8$; $\mathrm{AC} 9=10$ and 6-7=8) and 2 showed another $(\mathrm{TTC}=16 ; \mathrm{AC} 8 \mathrm{a}=10 ; \mathrm{AC} 9=11$ and 6-7=6). The multiple locus VNTR analysis showed two identical $M$. leprae VNTR profiles from Bandung and Surabaya which supports the use of VNTR loci for transmission studies.
\end{abstract}

\section{Introduction}

Leprosy is still considered a public health problem in Indonesia. The factors contributing to the high rates of incidence are still poorly understood. Auxiliary tools and knowledge are needed to address questions of source, routes and mode of infection and transmission. ${ }^{1,2}$ In recent years, to overcome these limitations, conventional epidemiology of leprosy has been aided by methods of genotyping Mycobacterium leprae (M. leprae). A more accurate description of leprosy transmission can then be provided by a synthesis of both molecular and epidemiological data, leading to more effective control of the disease. ${ }^{3,4}$

The study of the genetic diversity of $M$. leprae is of extreme importance. The genotyping methods can provide insights into the leprosy transmission network within populations and in addition, genomic markers can be experimentally evaluated in the population of interest. Studying the $M$. leprae genotypes in slit-skin smear (SSS) provides additional knowledge towards assessing the strains harbored by patients. ${ }^{5,6} \mathrm{SSS}$ specimens are collected in a less invasive manner than through skin biopsy (SB). In this study, our aim has been to apply Variable Number of Tandem Repeat (VNTR) loci typing to compare $M$. leprae isolates from Surabaya and Bandung leprosy patients. Multiple locus VNTR analysis has been proposed as a means of genotyping for tracking leprosy transmission. Many tandem repeats have been reported to be polymorphic with potential as genetic markers to differentiate strains of M.leprae. However the distribution of polymorphism can vary depending on the population. In this study, our aim was to measure the copy number of repeats in four genetic markers: TTC, AC8a, AC9 and 6-7 from SSS in leprosy patients from Surabaya and Bandung.

\section{Materials and Methods}

23 new leprosy patients who attended the Outpatient Clinic in Dr Soetomo Hospital Surabaya and 21 in Dr Hasan Sadikin Hospital Bandung were recruited. Multiple locus VNTR analysis at four loci was applied using total DNA extracts from SSS. All subjects were classified as multibacillary (MB) type of leprosy following standard clinical criteria from WHO. Informed consents were obtained from all the patients and the study was approved by the Organisation Ethical Committee of Dr Soetomo Hospital, Surabaya.
Correspondence: Cita Rosita Sigit Prakoeswa, Dermatology Venereology Dept, Faculty of Medicine, Universitas Airlangga - DR Soetomo Teaching Hospital, Jl. Mayjen. Prof. Dr. Moestopo, No. 47, Airlangga, Gubeng, Surabaya, East Java, 60286, Indonesia. Phone: +62811328199 - Fax: +62315501609. E-mail: drcita.rosita@gmail.com

Key words: M. leprae, genotyping, Variable number of tandem repeat, Slit skin smear, Surabaya, Bandung.

Contributions: CRSP, LD, MS, DA, MDA, data collecting and analyzing; CRSP, BBR manuscript writing; RW, MYL, IA, SI, manuscript reviewing and references search.

Conflict of interest: The authors declare no potential conflict of interest.

Received for publication: 1 February 2019. Accepted for publication: 6 February 2019.

This work is licensed under a Creative Commons Attribution-NonCommercial 4.0 International License (CC BY-NC 4.0).

(C) Copyright C.R.S. Prakoeswa, et al., 2019 Licensee PAGEPress, Italy

Dermatology Reports 2019; 11(s1):8017 doi:10.4081/dr.2019.8017

\section{Slit-skin specimens}

Slit-skin smear specimens were collected from the skin lesions of patients in the same manner as the routine slit-skin smear test for Bacterial Index examination. The samples on the disposable surgical blade were soaked into phosphate-buffered saline and kept in a freezer until use. The bacilli were removed from the blade and collected as a pellet by centrifugation at $16,000 \mathrm{~g}$ for $20 \mathrm{~min}$ at $4^{\circ} \mathrm{C}$ until served, and were then washed with phosphate-buffered saline during the isolation. The DNA extraction method used Qiagen:DNeasy tissue kit.

\section{M. leprae Detection}

The $M$. leprae gene in regio RLEP3 repetitive element (X17153) was chosen to be amplified with nested PCR by following a procedure described earlier (Dinar). Amplification will produce about $129 \mathrm{bp}$ for external (outer) and $99 \mathrm{bp}$ for internal (inner) product. PCR was carried out using a Premix G mixture of FailSafe PCR System Cat. No. FSP995G (EPICENTRE, Madison, WI, USA) in a $20 \mu \mathrm{l}$ volume of reaction mixture containing at least $0.1 \mathrm{pg}$ of genomic DNA in $2 \mu \mathrm{l}$ of template DNA solution and $2 \mu \mathrm{l}$ of $5 \mu \mathrm{M}$ primers using FailSafe PCR Enzyme Taq Mix 250 U@2.5 $\mathrm{U} / \mu$ l Cat. No. FS99250. Primers Lp1 5' 
TGCATGTCATGGCCTTG- AGG 3' and Lp2 5' CACCGATACCAG- CGGCAGAA 3' were produced by Takara (Japan) and the amplification was done in a thermal cycler machine (BioRadi-cycler) under the conditions of $2 \mathrm{~min}$ at $98^{\circ} \mathrm{C}$ for preheating, $20 \mathrm{sec}$ at $98^{\circ} \mathrm{C}$ for denaturation, $30 \mathrm{sec}$ at $56^{\circ} \mathrm{C}$ for annealing and $30 \mathrm{sec}$ at $72^{\circ} \mathrm{C}$ for elongation repeated for 35 cycles followed by prolonged extension of $5 \mathrm{~min}$ at $72^{\circ} \mathrm{C}$, then inactivation at $4 \mathrm{oC}$. Primers Lp3 5' TGAGGTGTCGGCGTGGTC 3' and Lp4 5',
CAGAAATGGTGCAAGGGA 3' were tested using amplicon under 2 minutes at $98^{\circ} \mathrm{C}$ for preheating, $20 \mathrm{sec}$ at $98^{\circ} \mathrm{C}$ for denaturation, $30 \mathrm{sec}$ at $56^{\circ} \mathrm{C}$ for annealing and $30 \mathrm{sec}$ at $72^{\circ} \mathrm{C}$ for elongation repeated for 30 cycles followed by prolonged extension of $5 \mathrm{~min}$ at $72^{\circ} \mathrm{C}$, then inactivation at $4^{\circ} \mathrm{C}$. The full length of this amplicon was separated by electrophoresis in 3\% HS agarose gel Code No. 312-01431 (Cambrex Bioscience, Rockland, ME, USA) using TBE (Tris-Boric-EDTA, pH 8.0) buffer at
$100 \mathrm{~V}$. All the positive samples were forwarded on for genotyping analysis. ${ }^{7}$

\section{Genotyping analysis}

Genotyping analysis for TTC, AC8a, AC9 and 6-7 was performed by following the procedure described earlier. ${ }^{7-9}$ PCR was carried out as described before and was made in a $50 \mu$ l volume of reaction mixture containing at least $0.1 \mathrm{pg}$ of genomic DNA in $5 \mu \mathrm{l}$ of template DNA solution and $2 \mu \mathrm{l}$ of $5 \mu \mathrm{M}$ primers. The primers were used for
A

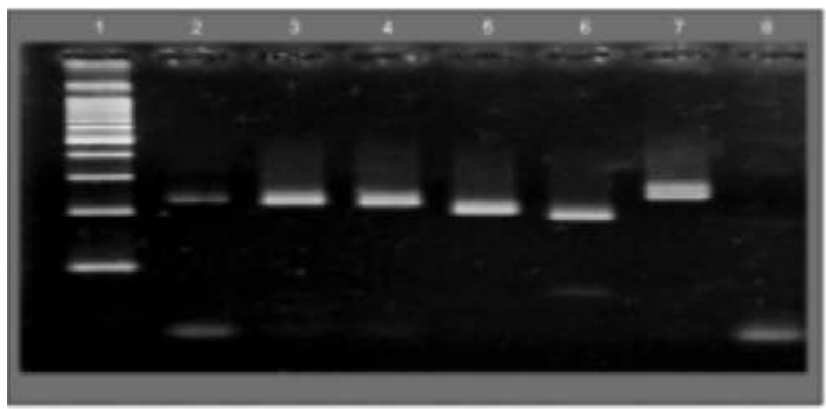

C

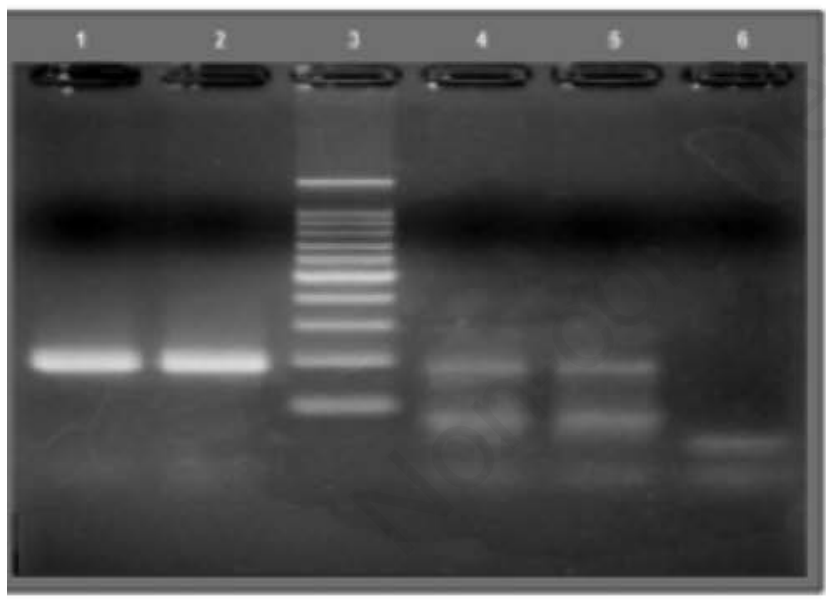

B

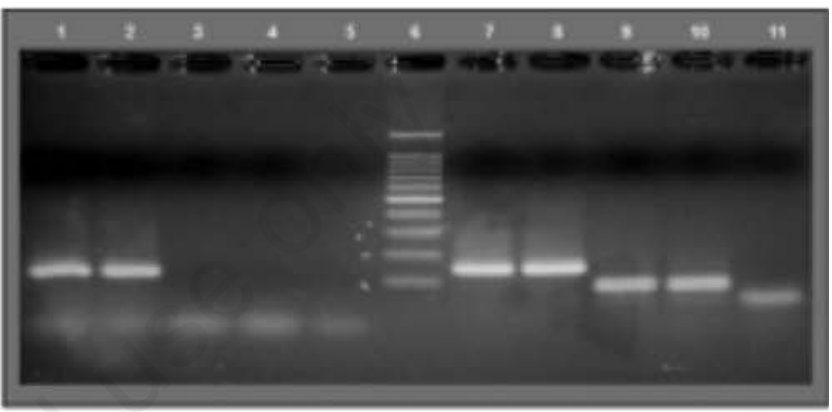

Figure 1. (A) Results of PCR genetic marker TTC. Lane 1: DNA ladder 100bp (marker); lane 2: positive control; lane 3-7: TTC repeat variation of PCR product; lane 8: negative control. (B) The result of PCR genetic marker AC 8a and AC9. Lane 1: positive control AC 8a; lane 2-4: AC 8a repeat variation of PCR product; lane 5: negative control AC 8a; lane 6: DNA ladder 100bp (marker); lane 7: positive control AC9; lane 8-10: AC9 repeat variation of PCR product; lane 11: negative control AC9. (C) The results of PCR genetic marker 6-7. Lane 1: positive control 6-7; lane 2,4,5: 6-7 repeat variation of PCR product; lane 3: DNA ladder 100 bp (marker); lane 6: negative control 6-7.

Table 1. The primers of VNTR: TTC, AC8a, AC9, 6-7.7-9

\begin{tabular}{lllll} 
VNIR locus & Product sive (b) & Tm & Forward & \\
TTC & 200 & $540 \mathrm{C}$ & GGA CCT AAA CCA TCC CGT TT & CTA CAG GGG GCA CTT AGC TC \\
AC8a & 124 & $570 \mathrm{C}$ & GTG TTA CGC GGA ACC AGG CA & CCA TCT GTT GGT ACT ACT GA \\
\hline AC9 & 146 & $620 \mathrm{C}$ & GCC TGG TGC CCG GAC AAT GC & ACA TCA CAC TGA TCT CGC CGG CGC T \\
$6-7$ & 191 & $620 \mathrm{C}$ & CTA CTT GCG CGC CAC CGC CA & GCC GTC GCC AGG TTT TGC AG \\
\hline
\end{tabular}


amplification and the Tm for genotyping analysis can be seen in Table 1. ${ }^{7-9}$ The numbers of VNTR repetitions were confirmed by direct sequencing. DNA samples for sequencing were recovered by GFXTM PCR, DNA and Gel Band Purification kits (Amersham Biosciences, GE Healthcare) with product code: $27-9602-01$ according to the manufacture's manual. Before sequencing reaction, the quantity and quality of purified DNA were examined by UV spectrophotometer. Dual CyDye TM Terminator Sequencing kits Cat. No 25-8226-01 (Amersham Biosciences, GE Healthcare) were used in the preparation of sequencing reaction. The mixture for cycle sequencing (labeling) was performed according to the manufacture's manual. The sequencing reaction was also done in a thermal cycler machine (BioRadi-cycler) under the following conditions: $20 \mathrm{sec}$ at $95^{\circ} \mathrm{C}, 15 \mathrm{sec}$ at (TM of sense primer +3$)^{\circ} \mathrm{C}, 1 \mathrm{~min}$ at $70 \mathrm{oC}$ and repeated for 35 cycles. The sequencing product was then purified by ethanol precipitation and dried followed by dissolving it in 21 of loading dye. It was then loaded into prepared acrylamide gel in Long-Read TowerTM System (Amersham Biosciences) Version 3.01. Sequence analysis was done by using Long-Read TowerTM System (Amersham Biosciences) with the temperature of $60 \mathrm{oC}$ as described in the protocol.

\section{Results}

Twenty three patients from Surabaya and twenty one from Bandung were evaluated. Samples show DNA detection using TTC primer (Figure 1A); AC 8a and AC9 primers (Figure 1B) and 6-7 primers (Figure 1C). All positive PCR result proceed with Genotyping Analysis (Figure 2).

The summary of results from the genotyping study is shown in Table 2 . There is a different distribution of genotyping M.leprae between the Surabaya and Bandung isolates. The multiple locus VNTR analysis shows two identical M.leprae VNTR profiles from Surabaya and Bandung, respectively. Samples 4, 5, 6, 7, 8, 9 and 10 and samples 13 and 14 from Surabaya show identical repetitive in 4 VNTR analysis.
Bandung samples 8 and 9 and samples 11 and 12 also show identical repetitive in 4 VNTR analysis.

\section{Discussion}

Molecular typing using genetic markers is thought to be an important tool in establishing strain-specific polymorphisms in $M$. leprae. This is important in determining and understanding the epidemiology of the disease. Currently, the approach towards molecular typing mainly involves locus-tolocus comparisons, such as microsatellite analysis. M. leprae is known to be uncultivable; in other words it cannot be cultured in artificial media, therefore it is often hard to obtain sufficient amounts of genomic DNA from clinical material. Therefore, an amplification-based technique is preferred and more applicable. Molecular typing is able to give useful information regarding global and geographical distribution of various strains of $M$. leprae which will ultimately aid in the study of transmission dynamics. To date, there are still relatively
A

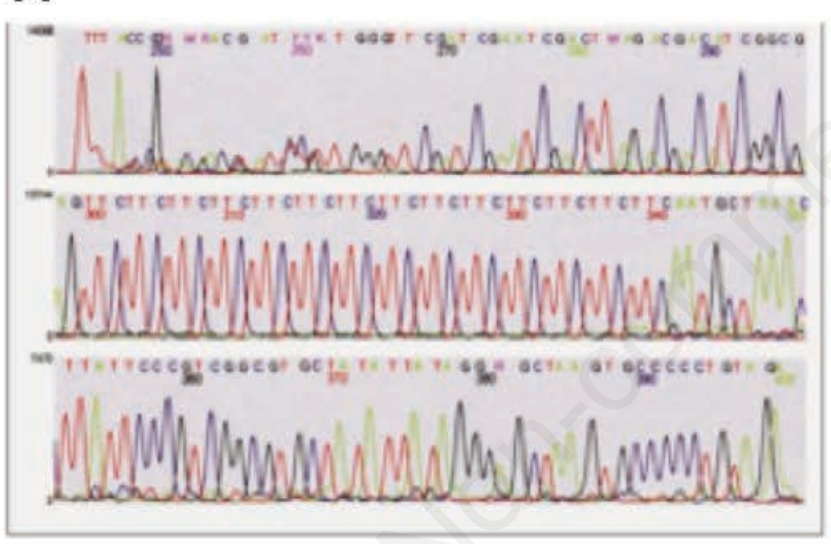

\section{C}

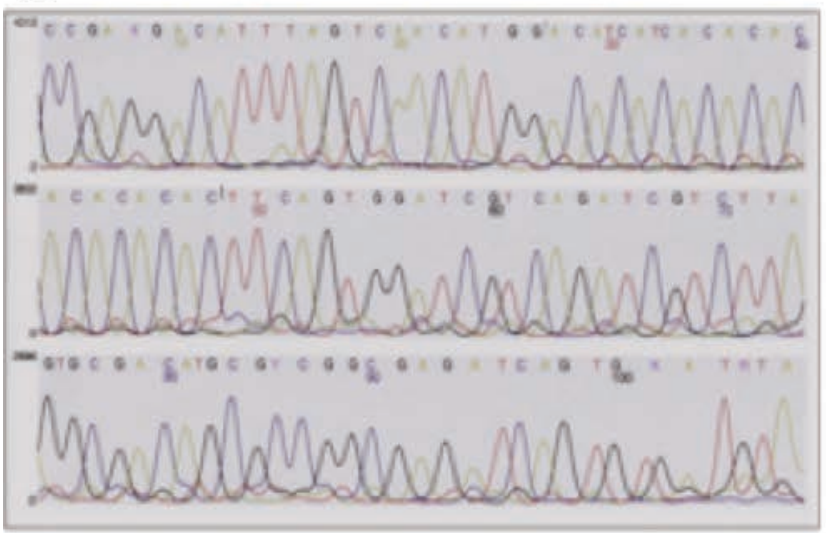

B

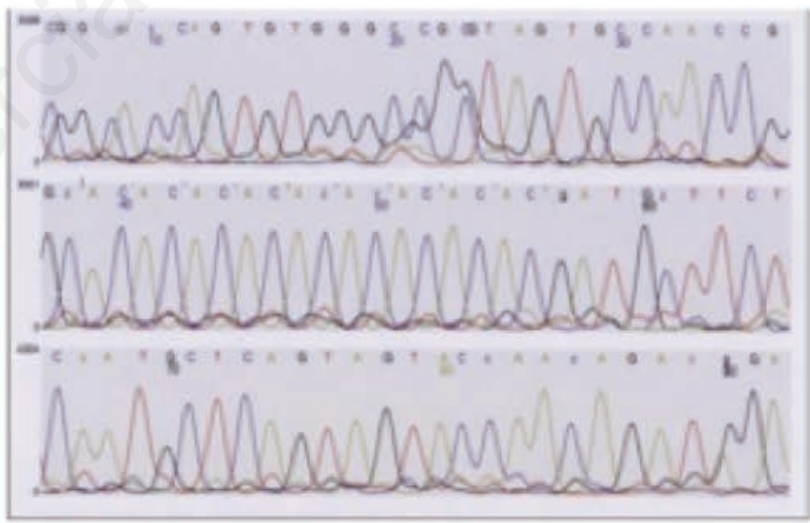

D

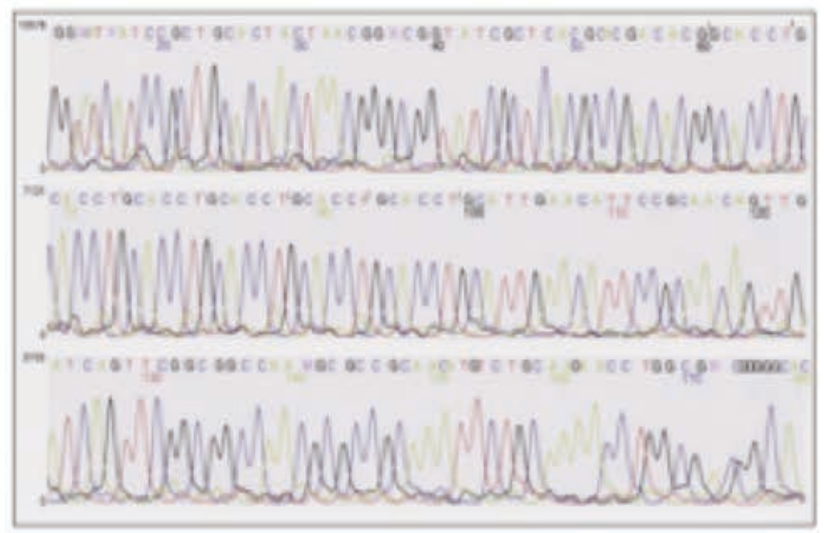

Figure 2. (A) Sequence of genetic marker TTC (14x); (B) sequence of genetic marker AC8a (9x); (C) sequence of genetic marker AC9 (10x); (D) sequence of genetic marker 6-7 (6x). 
Table 2. Clinical Isolate from Surabaya and Bandung.

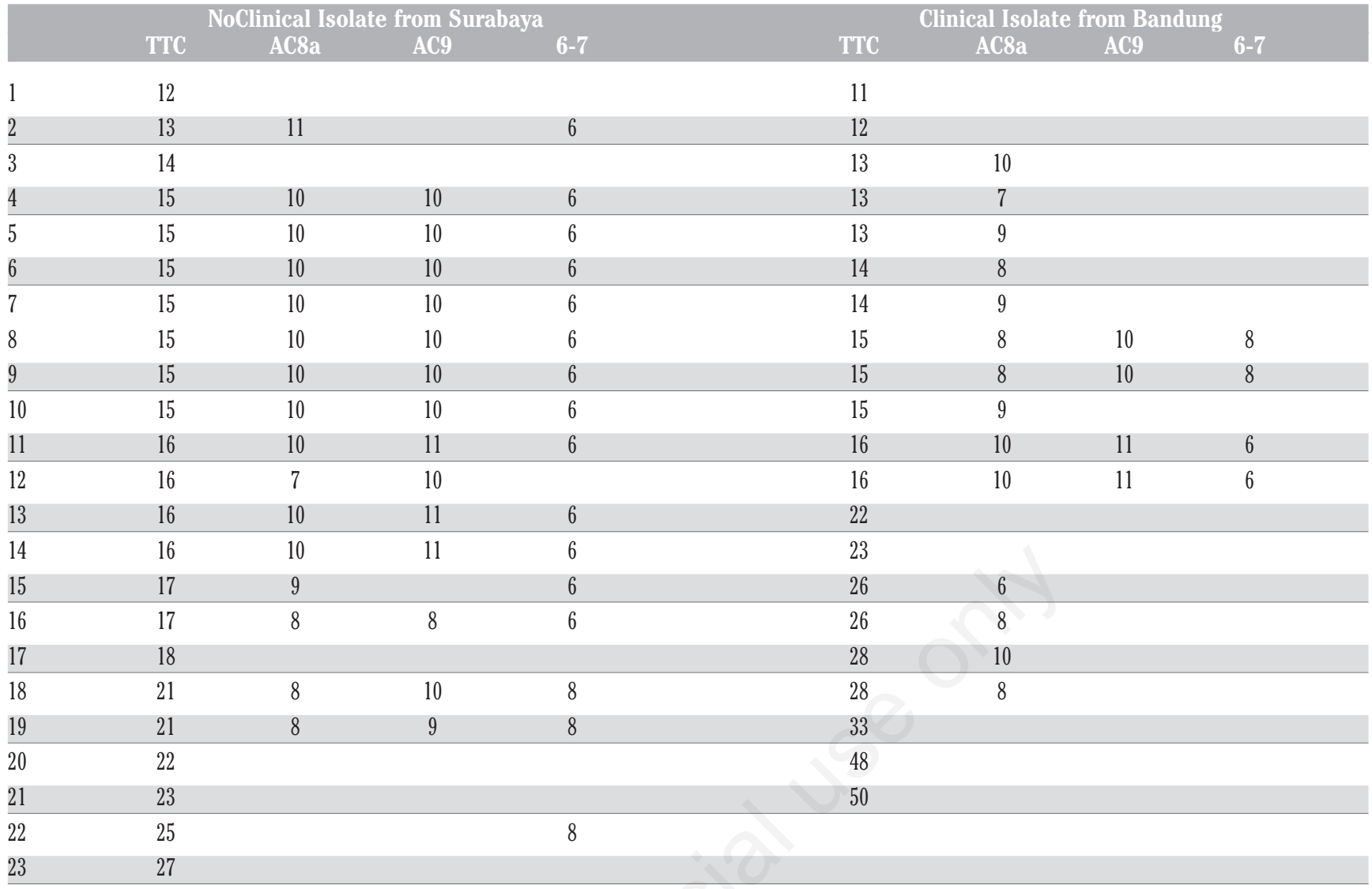

few researches which have investigated the use of markers to identify genotypic differences in $M$. leprae and the potential of this method is still the subject of much speculation. There is still very little information known regarding the genetic diversity of $M$. leprae in Indonesia which is still known to have a very high prevalence of leprosy. A new molecular system is needed to tackle this problem. Our study focuses on the identification of $M$. leprae strains from different parts of Indonesia (Surabaya and Bandung) by using 4 polymorphic loci VNTR. There is a variation in repeat lengths in the TTC (12-27 from Surabaya samples and 11-50 from Bandung samples); AC 8a (7-11 from Surabaya samples and 7-10 from Bandung samples); AC 9 (8-11 from Surabaya samples and 10-11 from Bandung samples); 6-7 (6-8 from Surabaya and Bandung samples). Among four VNTR types, we found TTC in all Surabaya samples and 21 out of 23 Bandung samples. These findings are different compared to other studes in Brazil, India and China. Analysis of allele frequencies of these VNTRs from published data from North India, ${ }^{10}$ South India, ${ }^{11}$ and Maharashtra, ${ }^{12}$ suggested a number of demographic associations among strains of M. leprae. Strains from Maharashtra and
South India have similar predominant allele except (AC)8a and 6-7. Our study showed that 8 and 6 allele were predominant respectively in our strains. Along with this, the strains from different countries like China, ${ }^{13}$ Brazil, ${ }^{14}$ Thailand, ${ }^{15}$ and the Philippines, ${ }^{16}$ the VNTR loci $(12-5,23-3,27-5,6-7$, (GTA)9) are showing similar dominant alleles across these countries except loci (AC) 8 b, (GGT) 5 and 21-3 which have a different allele in Philippine specimens. On the basis of allelic diversity indices, profiles of our strains were similar to those of South India and Maharashtra. (AC)9, (GTA)9 and 6-7 locus had high discriminatory index in our present study. These results suggest that molecular typing has a potential use as an effective tool to study the constantly changing M. leprae strains. The diversity by using these VNTRs is found to be similar within said countries but might be different in other countries. ${ }^{5}$

\section{Conclusions}

In conclusion, we have demonstrated with four multiple locus VNTR, the genetic diversity of $M$. leprae isolates from SSS Surabaya and Bandung patients. A different distribution of genotyping M.leprae was found between Bandung and Surabaya isolates. The multiple locus VNTR analysis showed two identical M.leprae VNTR profiles from Bandung and Surabaya, respectively. These attributes support the use of VNTR loci for transmission studies. Recommendations that follow are that, for better discrimination of the strains, more VNTR loci and other molecular markers suitable for typing genetic variations of the bacilli should be discovered. Since whole genomic sequencing is limited in developing countries, we need to improve classification systems capable of providing information on the M. leprae dynamics of transmission, and use these to help in the search for interventions that will reduce the number of new cases of leprosy.

\section{References}

1. World Health Organization. 2016. Global Leprosy Update, 2015: Time For Action, Accountability and Inclusion. Weekly Epidemiological Report, WHO: Geneva.

2. Ministry of Health Republic Indonesia. 
Annual Report. 2016. Profil Kesehatan Indonesia 2015. Jakarta.

3. Lima LNGC, Fontes ANB, Li W, et al. Intrapatient comparison of Mycobacterium leprae by VNTR analysis in nasal secretions and skin biopsy in a Brazilian leprosy endemic region. Lepr rev 2016;87:486-500.

4. Sun Z, Li W, Xu S, Huang H. The discovery, function and development of the variable number tandem repeats in different Mycobacterium species. Crit Rev Microbiol 2016;42:738-58.

5. Lavania M, Jadhav R, Turankar RP, et al. Genotyping of Mycobacterium leprae strains from a region of high endemic leprosy prevalence in India. Infect Genet Evol 2015;36:256-261.

6. Sakamuri RM, Kimura M, Li W, et al. Population-based molecular epidemiology of leprosy in Cebu, Philippines. J Clin Microbiol 2009; 47: 2844-2854.

7. Adriaty D, Wahyuni R, Aksono B. Variation of TTC Repeat Pattern In The Dna of Mycobacterium Leprae Isolates
Obtained from Archeological Bones and Leprosy Patients From East Nusa Tenggara. The Journal of Tropical Life Science 2012; 2: 87-91.

8. Lima LNC, Frota CC, Suffys PN, et al. Genotyping comparison of Mycobacterium leprae isolates by VNTR analysis from nasal samples in a Brazilian endemic region. Pathog Glob Health 2018;112:79-85.

9. Groathouse NA, Rivoire B, Kim H et al. Multiple Polymorphic Loci for Molecular Typing of Strains of Mycobacterium leprae. J Clin Microbiol 2004;42: 1666-1672.

10. Lavania M, Katoch K, Sharma R, et al. Molecular typing of Mycobacterium leprae strains from northern India using short tandem repeats. Indian J Med Res 2011;133:618-626.

11. Shinde V, Newton H, Sakamuri RM, et al. VNTR typing of Mycobacterium leprae in South Indian leprosy patients. Lepr rev 2009;80:290-301.

12. Kuruwa S, Vissa V, Mistrya N. Distribution of Mycobacterium leprae strains among cases in a rural and urban population of Maharashtra, India. J Clin Microbiol 2012;50:1406-1411.

13. Xing Y, Liu J, Sakamuri RM, et al. VNTR typing studies of Mycobacterium leprae in China: assessment of methods and stability of markers during treatment. Lepr rev 2009;80:261-71.

14. Fontes ANB, Sakamuri RM, Baptista IMFD, et al. 2009 Genetic diversity of mycobacterium leprae isolates from Brazilian leprosy patients. Lepr rev 2009; 80: 302-315.

15. Srisungnam S, Rudeeaneksin J, Lukebua A, et al. Molecular epidemiology of leprosy based on VNTR typing in Thailand. Lepr rev 2009;80:280-9.

16. Sakamuri RM, Harrison J, Gelber R, et al. A continuation: study and characterisation of Mycobacterium leprae short tandem repeat genotypes and transmission of leprosy in Cebu, Philippines. Lepr rev 2009; 80:272-9. 